UDK: 336.02(497.11)

DOI: 10.2478/jcbtp-2018-0007
"Economist, Roubini Global Economics, London, UK

\section{Estimated DSGE Model for Monetary and Fiscal Polic Coordination Analysis - The Case of Serbia}

\begin{abstract}
Apstract: We present a new-Keynesian model for small open economy, with price rigidities stemming from a Calvo pricing scheme (1983), monopolistic banking system, financial dollarization of the economy and monetary and fiscal policy governed by rules. We estimate the model on Serbian data and propose various model extensions that could be used for monetary and fiscal policy analysis. We consider 6 combinations of monetary and fiscal policy regimes, inflation targeting and currency peg on one hand, and discretionary cyclically neutral fiscal policy and fiscal rules, on the other. The model with inflation targeting and discretionary fiscal policy fits the data best.
\end{abstract}

Key Words: monetary policy, fiscal policy, DSGE model, coordination, Bayesian estimation

JEL classification: C15, E10, E12, E17, E52, E62, E63
Email:

tamara.basic-vasiljev@roubini.com

\title{
Introduction
}

We present a new-Keynesian DSGE model suitable for monetary and fiscal policy coordination analysis in a small open economy that deals with substantial financial dollarization. We estimate the model on data for Serbia, both to check the reliability of model calibration and to gain insight into the actual monetary and fiscal policy driving the Serbian economy. The estimation is done using Bayesian 
techniques and a Monte Carlo optimization routine supported by Dynare software package.

When it comes to monetary and fiscal policy coordination no consensus has been achieved either in literature or in practice on the level needed for coordination or predominance of monetary over fiscal policy (or vice versa). Attitudes about the needed level of coordination have changed over time, as have the choices of optimal monetary and fiscal policy. In this paper we focus our attention on exchange rate peg and inflation targeting as monetary policy regime choices on one hand, and on discretionary fiscal policy, cyclically neutral fiscal policy, and fiscal rules on the other hand. We approximate discretionary fiscal policy with an AR process, and we assume that cyclically neutral fiscal policy would be maintaining the same share of budget deficit in GDP. There is no consensus in literature (and much less in practice) on the optimal monetary or fiscal policy, but there seems to be an overwhelming support in literature for inflation targeting as an optimal monetary policy regime (and a growing list of countries implementing the policy), see Fisher (1995), Leiderman and Svensson (1995), Bernanke, Mishkin (1997), Bernanke et al (1998), Svensson (1997, 1999, 2000), Amer and Freeman (1995), Bernanke (2001), Mishkin and Schmidt-Hebbel (2001), Amato and Gerlach (2002), Truman (2003), Ball and Sheridan (2005), Gonçalvesa and Salles (2008). At the same time, fiscal rules are gaining support in literature and practice alike, see Hallerberg and von Hagen (2007), von Hagen (2003), Lagona and Padovano (2007), Ayuso-i-Casals et al (2007), Alesina et al (1999), Filc and Scartascini (2005), Caceras, Corbacho and Medina (2010), Dafflon and Pujol (2001), Feld and Kirchgessnaer (2006), Krogstrup and Waelti (2008), Alesina and Bayoumi (1996), and Fatas and Mihov (2006).

DSGE models are dominant in the literature in macroeconomics and economic policy fields, and are widely applied in practice. The Federal Reserve System, the Bank of England, the Swiss National Bank, the central banks of Canada, the Czech Republic, New Zealand, France, among others, use DSGE models for policy analysis and forecasts. Bayesian techniques of DSGE model estimation are most widely used, with their advantages documented in several papers, for example Schorfheide (2000), Smets, Wouters (2003), Rabanal, Rubio-Ramirez (2003), Fernandez-Villaverde, Rubio-Ramirez (2003, 2004), Lubik, Schorfheide (2007), An, Schorfheide (2007), Edge et al (2010).

The model we develop is a new-Keynesian model with price rigidities stemming from Calvo pricing scheme of the producing firms (1983). We model a small open economy, with influences from the world economy spilling over through imported inflation and foreign market interest rate. A special feature in the model 
is specification of financial dollarization of the economy, where financial holdings of the agents are denominated in domestic and foreign currency and priced at domestic and foreign currencies interest rates. The economy in the model is populated by households, firms, banks and central planners - monetary and fiscal authorities. Firms and banks are not integrated vertically, so we differentiate between producing and distributing firms, and investment and commercial banks. This distinction is pretty standard in literature, aiming at simplification of optimization problems for producer versus distributor firms, but few words of explanation are due in the case of banks since these terms are not used in the usual sense. Investment banks in our model are the ones managing the capital position of the banking sector, dealing only with commercial banks, while commercial banks deal with households and firms on one side, and investment banks on the other. Model is solved, log-linearized, calibrated and estimated on two sets of data. A full set of data (including banking sector interest rates) is only available since 2010, so we estimate the model on a smaller set of data (without the banking interest rates) for a longer period of time (since 2007) to get a robustness check.

The paper is organized as follows: we present the model equations by agents in section 2, in section 3 we present data used for the estimation and discuss the transformations necessary to fit the variables as defined in the model, section 4 comments the priors used and presents the estimation results, section 5 concludes, while in the appendix we present more estimation results and derive the log-linear version of the model.

\section{Model}

The model is a new-Keynesian model with price rigidities inhabited by households, firms, banks and central planners - monetary and fiscal authority. There are two types of firms, producers and distributors of finished goods, as well as two types of banks, we called them investment and commercial banks, where the investment banks in charge of the banking sector capital position and commercial banks are serving the clients - households and firms.

Source of nominal rigidities are prices since the firms are setting prices according to the Calvo (1983) pricing scheme, where only a portion of firms can change prices in a given period. Economy is a small and open economy, with influences from abroad being exogenous and spilling over through foreign interest rates, foreign inflation and an exchange rate. 


\section{Agents}

As already mentioned, agents in the economy are households, producer firms, distributor firms, investment banks, commercial banks, monetary authority, and fiscal authority.

\section{Households}

Every period households decide on the quantity of consumption and labour, while maximising the utility function of the following form:

$$
U=E_{0} \sum_{t=0}^{\infty} \beta^{t}\left[\frac{C(j)_{t}^{1-\chi}}{1-\chi}-N_{t}(j)\right]
$$

where $C_{t}$ is period $t$ consumption, $N_{t}$ is period $t$ labour, $\beta$ a discount factor and $\chi$ elasticity of substitution between the current and previous period that can also be seen as a degree of household's risk aversion.

All households are identical so the optimization problem is reduced to a representative household's problem.

In every period households have at their disposal income from labour, income from savings in domestic and foreign currency, and transfers from the budget, and they are spending them on current consumption and savings, again, in domestic and foreign currency, so that their budget constraint takes the following form:

$$
P_{t} C_{t}(j)+\mathrm{D}_{\mathrm{t}}=D_{t-1}^{d}(j)\left(1+i_{t-1}^{d d}\right)+S_{t} D_{t-1}^{f}(j)\left(1+i_{t-1}^{f d}\right)+W_{t} N_{t}(j)+\mathrm{G}_{t}
$$

where $P_{t}$ is consumer price index, $D_{t}^{f}$ are foreign currency deposits, $D_{t}^{d}$ are domestic currency deposits, $S_{t}$ is exchange rate, $\mathrm{W}_{t}$ are wages, $\mathrm{i}_{\mathrm{t}}^{\text {dd }}$ interest rate on domestic currency deposits, $\mathrm{i}_{t}^{d}$ interest rate on foreign currency deposits and $G_{t}$ are net budget transfer (social security transfers reduced by household tax).

Households cannot purchase government bonds (only investment banks can do this) and the government transfers are netted.

Total households deposits consist of two parts, one denominated in domestic and one denominated in foreign currency so that:

$$
D_{t}=D_{t}^{d}+S_{t} D_{t}^{f}
$$


where

$$
D_{t}^{d}=(1-\epsilon) D_{t} \text { and } S_{t} D_{t}^{f}=\epsilon D_{t}
$$

and $\varepsilon$ represents a share of savings denominated in foreign currency (degree of savings' dollarization). Since Serbia has a relatively high degree of financial dollarization (with approximately $75 \%$ of both savings and loans denominated in foreign currency, primarily euro) this is an important feature of the model.

Households are maximising utility function under the budget constraint which produces the following first order conditions:

$$
\begin{gathered}
C_{t}^{-\chi}=P_{t} \lambda_{t} \\
W_{t}=\frac{1}{\lambda_{t}}
\end{gathered}
$$

Where $\lambda_{t}$ is a Lagrange multiplier, and

$$
\beta^{t}\left\{-\lambda_{t}+\beta \lambda_{t+1}\left[(1-\varepsilon)\left(1+i_{t}^{d d}\right)+\varepsilon\left(1+i_{t}^{f d}\right) S_{t+1}\right]\right\}=0
$$

By combining first and third F.O.C. we obtain Euler equation defining the intertemporal consumption substitution:

$$
C_{t}^{-\chi}=\beta C_{t+1}^{-\chi}\left[(1-\varepsilon)\left(1+i_{t}^{d d}\right)+\varepsilon\left(1+i_{t}^{f d}\right) S_{t+1}\right] \frac{P_{t}}{P_{t+1}}
$$

By combining second and third F.O.C. we get:

$$
\frac{W_{t}}{P_{t}}=C_{t}^{-\chi}
$$

i.e. real wages definition, which in this case depends on current consumption and elasticity of substitution between current and previous period's consumption.

\section{Firms}

Firm is maximising profit under three constraints, its production function, which in our case has a Cobb Douglas form, demand function and price setting conditions. To simplify the problem one can divide the firms in vertical chain, and have a producer firms minimising costs and distributor firm maximising profit from sales. 
Producer firm produces a quantity $\mathrm{Y}_{t}$ and sells it to the distributor firm, while hiring labour $\mathrm{N}_{t}$ at a wage $\mathrm{W}_{t}$, and importing quantity $\mathrm{M}_{\mathrm{t}}$ at a price $\mathrm{P}_{\mathrm{t}}^{*}$. Firm also borrows, in both domestic and foreign currency, in order to finance its production, and repays the debt in every period, so that the cost function takes the form:

$$
C F=E_{0} \sum_{t=0}^{\infty} \Xi^{t}\left[P_{t}^{*} S_{t} M_{t}+W_{t} N_{t}+\left(\left(1+i_{t-1}^{d l}\right)(1-\epsilon)+\left(1+i_{t-1}^{f l}\right) \epsilon S_{t}\right) L_{t-1}\right]
$$

And its production function being:

$$
Y_{t}=A_{t} M_{t}^{\alpha} N_{t}^{1-\alpha}-\rho^{A} A_{t}
$$

where $A_{t}$ is technology used in production, $\rho^{A}$ is production fixed costs which grows together with technology, and $\alpha$ is elasticity of labour productivity.

Dollarization degree for the firms' debt is the same as for the household savings and the share of debt financed production is fixed, so that:

$$
L_{t}^{d}+S_{t} L_{t}^{f}=L_{t}=\kappa^{y} Y_{t}
$$

where $k^{y}$ is the share of debt financed production.

firm's production function is a standard Cobb Douglas production function where production factors are work and imports, and the production is dependent on technology level. Technology variable enters production function twice, as a factor increasing the product of work and imports, and as a proportional part of fixed costs, preventing the systematically positive profits in steady state.

Capital as a production factor is neglected, as is often the case in the DSGE models, due to the fact that capital is a particularly difficult variable to measure, where such data is not available for Serbia. Since we are estimating the model we decided to disregard capital as a variable.

Last two equations can be combined in a unique budget constraint:

$$
\begin{gathered}
\frac{L_{t}}{\kappa^{y}}=A_{t} M_{t}^{\alpha} N_{t}^{1-\alpha}-\rho^{A} A_{t} \\
L_{t}^{d}=(1-\epsilon) L_{t} \text { and } L_{t}^{f}=\epsilon L_{t}
\end{gathered}
$$

Firm's discount factor depends on households demand elasticity, i.e. on Lagrange multiplier definition from the household's maximisation problem: 


$$
\Xi_{t}=\beta \frac{\lambda_{t+1}}{\lambda_{t}}=\beta \frac{1}{\left(1+i_{t}^{d d}\right)(1-\epsilon)+\left(1+i_{t}^{f d}\right) \epsilon S_{t+1}}
$$

By differentiating the Lagrange function w.r.t. $\mathrm{N}_{\mathrm{t}}, \mathrm{M}_{\mathrm{t}}$ and $\mathrm{L}_{\mathrm{t}}$ we obtain the following first order conditions:

$$
\begin{gathered}
W_{t}=\lambda_{t}(1-\alpha)\left(\frac{Y_{t}}{N_{t}}\right) \\
P_{t}^{*} S_{t}=\lambda_{t} \alpha\left(\frac{Y_{t}}{M_{t}}\right) \\
\Xi\left(\left(1+i_{t}^{d l}\right)(1-\varepsilon)+\left(1+i_{t}^{f l}\right) \varepsilon S_{t+1}\right)=-\lambda_{t} \frac{1}{\kappa^{y}}
\end{gathered}
$$

where the Lagrange multiplier $\lambda_{t}$ can be seen as a marginal cost of the producer and by combining with first order, conditions can be expressed as a combination of work and imports prices:

$$
\lambda_{t}=r m c_{t}=W_{t}^{1+\alpha} \frac{1}{1-\alpha}\left(\frac{\alpha}{1-\alpha}\right)^{\alpha} \frac{1}{A_{t}}\left(\frac{1}{P_{t}^{*} S_{t}}\right)^{\alpha}
$$

Distributor firm purchases products of the producer firm at a price rmct (equal to the real marginal cost of the producer firm) and then sells it with maximising its profits:

$$
\Pi=E_{0} \sum_{t=0}^{\infty} \Xi^{t} \omega^{t}\left[P_{t}(f) Y_{t}(f)-r m c_{t} Y_{t}(f)\right]
$$

where $\mathrm{rmc}_{\mathrm{t}}$ is real marginal cost of the producer, and $\omega$ is the probability that the firm will change prices in period $t$, meeting the demand of the following form:

$$
Y_{t}(f)=\left(\frac{P_{t}(f)}{P_{t}}\right)^{-\theta} Y_{t}
$$

In the spirit of Calvo (1983) pricing scheme prices are optimized in period t only by $\omega$ portion of all firms.

By differentiating Lagrange function with respect to $P_{t}(f)$ we obtain the first order condition:

$$
\left(\frac{P_{t}(f)}{P_{t}}\right)=\left(\frac{\theta}{\theta-1}\right) \frac{\mathrm{E}_{t} \sum_{i=0}^{\infty} \omega^{i} \beta^{i} C_{t+i}^{1-\sigma} r m c_{t}\left(\frac{P_{t+i}}{P_{t}}\right)^{\theta}}{\mathrm{E}_{t} \sum_{i=0}^{\infty} \omega^{i} \beta^{i} C_{t+i}^{1-\sigma}\left(\frac{P_{t+i}}{P_{t}}\right)^{\theta}}
$$


i.e. the price setting rule for firms that optimize prices only in given periods.

If all firms would be optimizing prices every period (if $\omega=0$ ) this becomes:

$$
\left(\frac{P_{t}(f)}{P_{t}}\right)=\left(\frac{\theta}{\theta-1}\right) r m c_{t}
$$

Price index is formed in proportion of (1- $\omega$ ) based on optimal price for the firms optimizing in period $t$ and in proportion of $\omega$ based on optimal price set in the previous period, for the firms that cannot optimize prices in period t:

$$
P_{t}^{1-\vartheta}=(1-\omega) P_{t}(f)^{1-\theta}+\omega P_{t-1}^{1-\theta}
$$

If we define $Q_{t}$ as a relative price for the firms optimizing prices in period $t$ :

$$
Q_{t}=\frac{P_{t}(f)}{P_{t}}
$$

then it holds that:

$$
1=(1-\omega) Q_{t}^{1-\theta}+\omega{\frac{P_{t-1}}{P_{t}}}^{1-\theta}
$$

By combining price setting rule (20), price margin (21) and relative price (24) we obtain:

$$
Q_{t} \mathrm{E}_{t} \sum_{i=0}^{\infty} \omega^{i} \beta^{i} C_{t+i}^{1-\sigma}\left(\frac{P_{t+i}}{P_{t}}\right)^{\theta-1}=\mathrm{E}_{t} \sum_{i=0}^{\infty} \omega^{i} \beta^{i} C_{t+i}^{1-\sigma} r m c_{t+i}\left(\frac{P_{t+i}}{P_{t}}\right)^{\theta}
$$

from which a Keynesian Philips curve can be obtained, linking inflation to real marginal cost:

$$
\pi_{t}=\frac{(1-\omega)(1-\beta \omega)}{\omega} r m c_{t}+\beta \pi_{t+1}
$$

This equation is presented in log-linearized form for easier derivation.

\section{Banks}

Similar to firms, banks are maximising profits under the budget constraint. In the model they are working in an environment of limited (monopolistic) competition, in a spirit of the paper Geralli et al (2009). In the model we make a distinction between the investment and commercial banks, where investment banks are 
handling the capital position of the mother bank, while the commercial banks are working with the clients - households and firms, collecting deposits and granting loans.

Model includes currency duality in bank balance sheets, since Serbian economy is characterised by high degree of financial dollarization. Optimization problem of the banks is thus made more complicated by introducing different interest rates for different currency denominations of deposits and loans. On the other hand, influence of bank regulation (through reserve requirements for example) is omitted in the model, since we assumed that this issue does not crucially influence the question of monetary and fiscal policy coordination we are investigating. This has been a popular topic in the literature since the 2007 crisis (see Goodfriend, McCallum (2007), Curida, Woodford (2009), Dib (2010), Giannoni, Woodford (2010), Dewachter, Wouters (2012)).

Investment banks collect deposits Dt from commercial banks and borrow abroad, using these funds to lend to the commercial banks Lt and invest in government bonds Bt. Both deposits and loans can be denominated in domestic and in foreign currency. In accordance with the bank regulations investment banks must maintain a certain proportion of deposits to loans $(\eta)$, and in case they violate this stipulation they pay the penalty (п) thus decreasing their profit.

$$
\Pi=f\left(\frac{L_{t}+B_{t}}{D_{t}}, \eta\right)=\frac{\kappa^{\Pi}}{2}\left(\frac{L_{t}+B_{t}}{D_{t}}-\eta\right)^{2}\left(L_{t}+B_{t}\right)
$$

Penalty for capital adequacy violation has a quadratic form to insure favourable characteristics of the dynamic solution. Linear function would result in negligible capital adequacy requirement influence on bank margins, as we shall see in the text. Note that we do not use a variable of bank capital in the model, though it is easily expressed as a residual of loans and deposits, and the intention is simplification, similar to that used in the case of firms.

Banks maximise profit:

$$
\Pi=\sum_{t=0}^{\infty} \Xi^{t}\left[\begin{array}{c}
(1+) L_{t-1}^{d}+\left(1+i_{t-1}^{w f l}\right) S_{t} L_{t-1}^{f}+\left(1+i_{t-1}^{b}\right) B_{t-1}-L_{t}-B_{t} \\
-\left(1+i_{t-1}^{w d d}\right) D_{t-1}^{d} \\
-\left(1+i_{t-1}^{w f d}\right) S_{t} D_{t-1}^{f}-\left(1+i_{t-1}^{*}\right) S_{t} P R E M_{t} F B_{t-1} \\
+D_{t}+S_{t} F B_{t}-\left(\frac{L_{t}+B_{t}}{D_{t}}-\eta\right)
\end{array}\right]
$$

under the budget constraint, bank balance sheet: 


$$
L_{t}^{d}+S_{t} L_{t}^{f}+B_{t}=D_{t}^{d}+S_{t} D_{t}^{f}+S_{t} F B_{t}
$$

By using the budget constraint twice the problem can be simplified to:

$$
\begin{gathered}
\Pi=\sum_{t=0}^{\infty} \Xi^{t}\left[i_{t-1}^{w d l} L_{t-1}^{d}+i_{t-1}^{w f l} S_{t} L_{t-1}^{f}+i_{t-1}^{b} B_{t-1}-i_{t-1}^{w d d} D_{t-1}^{d}-i_{t-1}^{w f d} S_{t} D_{t-1}^{f}\right. \\
\left.-i_{t-1}^{*} S_{t} P R E M_{t} F B_{t-1}-\frac{\kappa^{\Pi}}{2}\left(\frac{L_{t}+B_{t}}{D_{t}}-\eta\right)^{2}\left(L_{t}+B_{t}\right)\right]
\end{gathered}
$$

Solving this problem we obtain the first order conditions,

by differentiating w.r.t. $\mathrm{FB}_{\mathrm{t}}$ :

$$
\Xi i_{t}^{*} P R E M_{t+1} S_{t+1}-\lambda_{t} S_{t}
$$

by differentiating w.r.t. $\mathrm{D}_{\mathrm{t}}^{\mathrm{b}}$ :

$$
-\Xi i_{t}^{w d d}+\kappa^{\Pi}\left(\frac{L_{t}+B_{t}}{D_{t}}-\eta\right)\left(\frac{L_{t}+B_{t}}{D_{t}}\right)^{2}(1-\varepsilon)+\lambda_{t}=0
$$

by differentiating w.r.t. $\mathrm{D}_{\mathrm{t}}^{\mathrm{f}}$ :

$$
-\Xi i_{t}^{w f d} S_{t+1}+\kappa^{\Pi}\left(\frac{L_{t}+B_{t}}{D_{t}}-\eta\right)\left(\frac{L_{t}+B_{t}}{D_{t}}\right)^{2} \varepsilon S_{t}+\lambda_{t} S_{t}=0
$$

by differentiating w.r.t. $\mathrm{L}_{\mathrm{t}}^{\mathrm{d}}$ :

$$
\Xi i_{t}^{w d l}-\kappa^{\Pi}\left(\frac{L_{t}+B_{t}}{D_{t}}-\eta\right)\left(\frac{L_{t}+B_{t}}{D_{t}}\right)(1-\varepsilon)-\lambda_{t}=0
$$

by differentiating w.r.t. $\mathrm{L}_{\mathrm{t}}^{\mathrm{f}}$ :

$$
\Xi i_{t}^{w f l} S_{t+1}-\kappa^{\Pi}\left(\frac{L_{t}+B_{t}}{D_{t}}-\eta\right)\left(\frac{L_{t}+B_{t}}{D_{t}}\right) \varepsilon S_{t}-\lambda_{t} S_{t}=0
$$

by differentiating w.r.t. $\mathrm{B}_{\mathrm{t}}$ :

$$
\Xi i_{t}^{b}-\kappa^{\Pi}\left(\frac{L_{t}+B_{t}}{D_{t}}-\eta\right)\left(\frac{L_{t}+B_{t}}{D_{t}}\right)-\lambda_{t}=0
$$

Rearranging gives the following relations: 


$$
\begin{gathered}
i_{t}^{w d d}=i_{t}^{*} P R E M_{t} \frac{S_{t+1}}{S_{t}}+\kappa^{\Pi}(1-\varepsilon)\left(\frac{L_{t}+B_{t}}{D_{t}}-\eta\right)\left(\frac{L_{t}+B_{t}}{D_{t}}\right)^{2} \\
i_{t}^{w d l}=i_{t}^{*} P R E M_{t} \frac{S_{t+1}}{S_{t}}+\kappa^{\Pi}(1-\varepsilon)\left(\frac{L_{t}+B_{t}}{D_{t}}-\eta\right)\left(\frac{L_{t}+B_{t}}{D_{t}}\right) \\
i_{t}^{w f d} S_{t+1}=i_{t}^{*} P R E M_{t} S_{t+1}+\kappa^{\Pi} \varepsilon\left(\frac{L_{t}+B_{t}}{D_{t}}-\eta\right)\left(\frac{L_{t}+B_{t}}{D_{t}}\right)^{2} \\
i_{t}^{w f l} S_{t+1}=i_{t}^{*} P R E M_{t} S_{t+1}+\kappa^{\Pi} \varepsilon\left(\frac{L_{t}+B_{t}}{D_{t}}-\eta\right)\left(\frac{L_{t}+B_{t}}{D_{t}}\right)
\end{gathered}
$$

and:

$$
i_{t}^{b}=i_{t}^{w d l}
$$

where $S_{t}^{D}=\kappa^{\Pi} m^{c}\left(\frac{L_{t}+B_{t}}{D_{t}}-\eta\right)\left(\frac{L_{t}+B_{t}}{D_{t}}\right)^{2}$ is the interest rate margin for deposits and $S_{t}^{L}=\kappa^{\Pi} m^{c}\left(\frac{L_{t}+B_{t}}{D_{t}}-\eta\right)\left(\frac{L_{t}+B_{t}}{D_{t}}\right)$ is the interest rate margin for loans and $\quad m^{c}=\left\{\begin{array}{rr}\varepsilon \text { for loans and deposits denominated in domestic currency } \\ 1-\varepsilon\end{array}\right\}$

By introducing penalty for the inadequate deposits level we get the differentiation between the lending and deposits rates. One could also introduce reserve requirements and differentiate it by currencies in order to inspect the effects of such prudential measures on the system.

Interest rate on government bonds in the model is equal to the interest rate on corporate lending, which does not stray far from the observed data for the Serbian economy. Differentiating those two rates could give us the opportunity to investigate issues such as crowding out effect of the public spending.

Commercial banks distribute loans to their final users, firms, whilst maximising profit by setting the loan price, i.e. interest rate. Borrowing from the investment banks at rates $i_{t}^{\text {wdl }}$ and $i_{t}^{\text {wfl }}$, in domestic and foreign currency respectively, and issue loans at rates $i(j)_{t}^{d l}$ and $i(j)_{t}^{f l}$, in domestic and foreign currency respectively. Bank bears the cost of changing the interest rate, which is represented as a quadratic function with parameters $\kappa^{\mathrm{dd}}$ and $\kappa^{\mathrm{fd}}$, for loans in domestic and foreign currencies. Bank solves the following optimization problem: 


$$
\Pi=\sum_{t=0}^{\infty} \Xi_{t}\left[\begin{array}{c}
i(j)_{t}^{d l} L(j)_{t}^{d}+i(j)_{t}^{f l} S_{t} L(j)_{t}^{f}-i_{t}^{w d l} L(j)_{t}^{d}-i_{t}^{w f l} S_{t} L(j)_{t}^{f} \\
-\frac{\kappa^{d d}}{2}\left(\frac{i(j)_{t}^{d l}}{i(j)_{t-1}^{d l}}-1\right)^{2} i(j)_{t}^{d l} L(j)_{t}^{d}-\frac{\kappa^{f d}}{2}\left(\frac{i(j)_{t}^{f l}}{i(j)_{t-1}^{f l}}-1\right)^{2} i(j)_{t}^{f l} S_{t} L(j)_{t}^{f}
\end{array}\right]
$$

constrained by the demand functions for loans in domestic and foreign currency:

where:

$$
L(j)_{t}^{d}=\left[\frac{i(j)_{t}^{d l}}{i_{t}^{d l}}\right]^{-\varepsilon^{d d}} L_{t}^{d}, \quad L(j)_{t}^{f}=\left[\frac{i(j)_{t}^{f l}}{i_{t}^{f l}}\right]^{-\varepsilon^{f d}} L_{t}^{f}
$$

$$
L_{t}=L_{t}^{d}+L_{t}^{f}
$$

solving this optimization problem by interest rates $i_{t}{ }^{\mathrm{dl}}$ and $i_{t}{ }^{f l}$, and having in mind that all banks are identical and the solution is thus symmetrical so that:

and

$$
L(j)_{t}^{d}=L_{t}^{d} \quad \text { and } \quad L(j)_{t}^{f}=L_{t}^{f}
$$

$$
i(j)_{t}^{d l}=i_{t}^{d l} \quad \text { and } \quad i(j)_{t}^{f l}=i_{t}^{f l}
$$

we obtain the following first order conditions:

$1-\varepsilon^{d l}+\varepsilon^{d l} \frac{i_{t}^{w d l}}{i_{t}^{d l}}-\kappa^{d l}\left(\frac{i_{t}^{d l}}{i_{t-1}^{d l}}-1\right)+\beta \frac{\Xi_{t+1}}{\Xi_{t}} \kappa^{d l}\left(\frac{i_{t+1}^{d l}}{i_{t}^{d l}}-1\right)\left(\frac{i_{t+1}^{d l}}{i_{t}^{d l}}\right)^{2} \frac{L_{t+1}^{d}}{L_{t}^{d}}=0$

and

$\left(1-\varepsilon^{f l}\right) S_{t}+\varepsilon^{f l} \frac{i_{t}^{w f l}}{i_{t}^{f l}} S_{t}-\kappa^{f l}\left(\frac{i_{t}^{f l}}{i_{t-1}^{f l}}-1\right) S_{t}+\beta \frac{\Xi_{t+1}}{\Xi_{t}} \kappa^{f l}\left(\frac{i_{t+1}^{f l}}{i_{t}^{f l}}-1\right)\left(\frac{i_{t+1}^{f l}}{i_{t}^{f l}}\right)^{2} S_{t} \frac{L_{t+1}^{f}}{L_{t}^{f}}=$

On the other hand commercial banks collect deposits from the households paying rates $\mathrm{i}^{\mathrm{dd}}$ and $\mathrm{i}^{\mathrm{fd}}$, for deposits denominated in domestic and foreign currency, and deposit them with the investment bank at rated $i^{\text {wdd }}$ and $i^{\text {wfd }}$, for deposits in domestic and foreign currency respectively. In the same way as commercial banks bear costs of changing interest rates when granting loans, they beat them when they change the interest rates on deposits, which is again represented as a quadratic function with parameters $\kappa^{\mathrm{dd}}$ and $\kappa^{\mathrm{fd}}$, for deposits in domestic and foreign currency. Interest rate margin of the commercial bank is defined by these parameters. 
Bank solves the following optimisation problem:

$$
\begin{gathered}
\Pi=\sum_{t=0}^{\infty} \Xi_{t} j\left[i_{t}^{w d d} D(j)_{t}^{d}+i_{t}^{w f d} S_{t} D(j)_{t}^{f}-i(j)_{t}^{d d} D(j)_{t}^{d}-i(j)_{t}^{f d} S_{t} D(j)_{t}^{f}-\frac{\kappa^{\mathrm{dd}}}{2}\left(\frac{i(j)_{t}^{d d}}{i(j)_{t-1}^{d d}}\right)^{2} i_{t}^{d d} D(j)_{t}^{d}\right. \\
\left.-\frac{\kappa^{\mathrm{fd}}}{2}\left(\frac{i(j)_{t}^{f d}}{i(j)_{t-1}^{f d}}\right) i_{t}^{f d} D(j)_{t}^{f}\right]
\end{gathered}
$$

constrained by the demand function for deposits in domestic and foreign currency:

$$
D(j)_{t}^{d}=\left[\frac{i(j)_{t}^{d d}}{i_{t}^{d d}}\right]^{-\varepsilon^{d d}} D_{t}^{d} \quad \text { and } \quad D(j)_{t}^{f}=\left[\frac{i(j)_{t}^{f d}}{i_{t}^{f d}}\right]^{-\varepsilon^{f d}} D_{t}^{f}
$$

By solving this optimisation problem w.r.t. interest rates $i_{t}^{\mathrm{dd}}$ and $i_{t}^{\mathrm{df}}$ and having in mind that all banks are identical so that:

$$
D(j)_{t}^{d}=D_{t}^{d} \quad \text { and } \quad D(j)_{t}^{f}=D_{t}^{f}
$$

and

$$
i(j)_{t}^{d d}=i_{t}^{d d} \quad \text { and } \quad i(j)_{t}^{f d}=i_{t}^{f d}
$$

the following first order conditions are obtained:

$-1+\varepsilon^{d d}-\varepsilon^{d d} \frac{i_{t}^{w d d}}{i_{t}^{d d}}-\kappa^{\mathrm{dd}}\left(\frac{i_{t}^{d d}}{i_{t-1}^{d d}}-1\right) \frac{i_{t}^{d d}}{i_{t-1}^{d d}}+\beta \frac{\Xi_{t+1}}{\Xi_{t}} \kappa^{\mathrm{dd}}\left(\frac{i_{t+1}^{d d}}{i_{t}^{d d}}-1\right)\left(\frac{i_{t+1}^{d d}}{i_{t}^{d d}}\right)^{2} \frac{D_{t+1}^{d}}{D_{t}^{d}}=0$

And

$$
\begin{gathered}
\left(-1+\varepsilon^{f d}\right) S_{t}-\varepsilon^{f d} \frac{i_{t}^{w f d}}{i_{t}^{f d}} S_{t}-\kappa^{\mathrm{dd}}\left(\frac{i_{t}^{f d}}{i_{t-1}^{f d}}-1\right) S_{t} \frac{i_{t}^{f d}}{i_{t-1}^{f d}} \\
+\beta \frac{\Xi_{t+1}}{\Xi_{t}} \kappa^{\mathrm{fd}}\left(\frac{i_{t+1}^{f f}}{i_{t}^{f d}}-1\right)\left(\frac{i_{t+1}^{f d}}{i_{t}^{f d}}\right)^{2} S_{t} \frac{D_{t+1}^{f}}{D_{t}^{f}}=0
\end{gathered}
$$

\section{Central planner (monetary authority)}

In the model, monetary policy is set by the central bank which, as other agents in the economy, solves an optimization problem where it minimizes the sum of deviations of targeted variables from the target, under the constraints of the system. In this case constraints of the system are the new-Keynesian Philips curve and the IS curve and the targeted values are inflation rate and output gap. Since the central bank also aims at stability and predictability of its policy, we add a 
neutral interest rate to the loss function around which the central bank aims to stabilize its reference rate.

Put mathematically, the central bank chooses the interest rate to minimise the loss function:

$$
L_{t}=\sum_{t}^{\infty} \beta^{t}\left(\pi_{t}-\pi_{t}^{T}\right)^{2}+x_{t}^{2}+\left(i_{t}^{d d}-i_{t}^{n}\right)^{2}
$$

where $\pi_{t}^{\mathrm{T}}$ is the inflation target, $\mathrm{x}_{t}$ is the output gap, i.e. deviation of gross domestic product from its potential level, and $i_{t}{ }^{n}$ is the neutral interest rate around which the central bank wants to stabilize the reference rate. As both positive and negative deviation is unwanted deviations are given in quadratic form.

The central bank is constrained by the Philips curve:

$$
\pi_{t}=\frac{(1-\omega)(1-\beta \omega)}{\omega} x_{t}+\beta \pi_{t+1}
$$

where $\mathrm{x}_{\mathrm{t}}$ is output gap, i.e. deviation of gross domestic product from its target:

$$
x_{t}=y_{t}-y_{t}^{T}
$$

and IS curve:

$$
x_{t}=x_{t+1}-\frac{1}{\chi}\left[i_{t}^{d d}(1-\varepsilon)+i_{t}^{f d} \varepsilon+\Delta s_{t}-\pi_{t+1}\right]
$$

First order conditions for this optimisation problem are:

$$
2 x_{t}+\mu \varphi_{t}^{1}-\varphi_{t}^{2}=0
$$

where $\varphi 1$ is the Lagrange coefficient for the first budget constraint, $\varphi 2$ is the Lagrange coefficient for the second budget constraint and

$$
\begin{aligned}
& \mu=\frac{(1-\omega)(1-\beta \omega)}{\omega} \\
& 2\left(\pi_{t}-\pi_{t}^{T}\right)-\varphi_{t}^{1}=0
\end{aligned}
$$

and

$$
2\left(i_{t}^{d d}-i_{t}^{n}\right)-\varphi_{t}^{2}(1-\epsilon) \frac{1}{\chi}=0
$$

By combining the three first order conditions we obtain the relation: 


$$
x_{t}+\mu\left(\pi_{t}-\pi_{t}^{T}\right)=\frac{\chi}{1-\epsilon}\left(i_{t}^{d d}-i_{t}^{n}\right)
$$

or:

$$
i_{t}^{d d}=i_{t}^{n}+\frac{1-\epsilon}{\chi}\left[\mu\left(\pi_{t}-\pi_{t}^{T}\right)+x_{t}\right]
$$

which says that the central bank will increase the reference rate when inflation is above its target, and/or output gap is positive, and vice versa.

Target inflation rate is defined as an AR process:

$$
\log \left(\pi_{t}^{T}\right)=\left(1-\rho^{\pi^{T}}\right) \log \left(\pi_{t-1}^{T}\right)+\varepsilon_{t}^{\pi^{T}}
$$

where $\rho^{\pi^{\mathrm{T}}} \in(0,1)$ and $\varepsilon_{\mathrm{t}}^{\pi^{\mathrm{T}}} \sim \mathcal{N}\left(0, \sigma^{2}\right)$ and $\sigma 2$ is very small in order to insure that the inflation target does not vary much from period to period, which is in line with the inflation targeting principle of stable and predictable monetary policy.

Modelling inflation target as an AR process is a standard solution in the literature. Ireland (2006) uses AR process which includes technology innovation, i.e. standard error of the Phillips curve on top of standard error of the inflation target process, and which can be seen as a cost push shock. In this way one insures that the central bank reacts to real shocks in the economy. Neri and Ropele (2015) use autoregressive process with added constant to simulate observed fact that the inflation target converges to a constant in the long run.

On the other hand, the central bank can implement a more or less strict regime of exchange rate peg. The IMF distinguishes several forms of currency rate fixing, from currency board and fixed peg to fixed peg with a horizontal band and crawling peg $^{1}$. We consider several forms of modelling a fixed exchange rate regime.

Mathematically we can model a fixed exchange rate regime in a simple formulation (like in Gali and Monacelli, 2000, 2005):

$$
S_{t}=S_{t-1}
$$

where $S_{t}$ is nominal exchange rate, or

$$
\Delta S_{t}=0
$$

1 IMF classification of monetary policy regimes is available at https://www.imf.org/external/np/mfd/er/2006/eng/0706.htm. 
where $\Delta \mathrm{S}_{\mathrm{t}}$ is the nominal exchange rate change (i.e. rate of depreciation/appreciation).

This kind of stability can be achieved in practice using a set of policy measures and interventions in a foreign currency market, among other things, so that the standard optimization problem solved by the central bank, that would include exchange rate stabilization among other things:

$$
L_{t}=\sum_{t}^{\infty} \beta^{t}\left(s_{t}-s_{t}^{T}\right)^{2}+x_{t}^{2}+\left(i_{t}^{d d}-i_{t}^{n}\right)^{2}
$$

where $S_{t}^{T}$ is targeted exchange rate, $\mathrm{x}_{\mathrm{t}}$ output gap, itn neutral intrest rate around which we want to stabilize the reference rate, or in the form

$$
L_{t}=\sum_{t}^{\infty} \beta^{t}\left(s_{t}-s_{t-1}\right)^{2}+x_{t}^{2}+\left(i_{t}^{d d}-i_{t}^{n}\right)^{2}
$$

cannot produce exchange rate stability observed in countries with the fixed exchange rate regime.

\section{Central planner (fiscal policy)}

Fiscal policy can be summed up as an optimization problem of the central planner, in this case the Government. Central planner is constrained by the budget, which in its simplest form boils down to:

$$
B_{t}=\left(1+i_{t-1}^{B}\right) B_{t-1}+G_{t}
$$

where $B_{t}$ is public debt, $i_{t}^{B}$ is interest rate on public debt (treasury bonds) and $G_{t}$ is the budget deficit, or net transfer from the Government to the agents in the economy (in this case households).

More complex forms of the budget constraint would include various forms of taxation and budgetary outlays, where one could make a distinction between transfers to the households versus transfers to the firms and/or banks, and taxes could be levied on different tax bases. For example:

$$
P D_{t}=\tau^{C} C_{t}+\tau^{W} W_{t}-T_{t}^{H}-T_{t}^{F}
$$

and

$$
B_{t}=\left(1+i_{t-1}^{B}\right) B_{t-1}+P D_{t}
$$


where $\mathrm{PD}_{\mathrm{t}}$ is the primary budget deficit, $\mathrm{C}_{\mathrm{t}}$ is the household consumption, $\mathrm{W}_{\mathrm{t}}$ wages, $\mathrm{T}_{t}^{\mathrm{H}}$ transfers to households, $\mathrm{T}_{\mathrm{t}}^{\mathrm{F}}$ transfers to firms, $\mathrm{B}_{t}$ pubic debt and $\mathrm{i}_{\mathrm{t}}^{\mathrm{B}}$ interest rate on treasury bonds.

In this model we don't make these distinctions starting from a premise that taxes are not distortive, i.e. do not influence agents' decision making. We assume that this assumption will not affect differences between analysed fiscal policy regimes.

We are considering three regimes: discretionary fiscal policy, where fiscal deficit is an AR process, procyclical fiscal policy, where fiscal deficit is in constant proportion to gross domestic product, and fiscal policy defined by fiscal rules.

In the first case, budget deficit is defined in the following way:

$$
G_{t}=\rho_{G} G_{t-1}+\varepsilon_{t}
$$

where $\varepsilon_{t}$ is white noise, and $\rho^{G}$ is the autocorrelation coefficient, i.e. degree of rigidity of budget deficit.

In the second case of fiscal cycle neutrality, the following relation holds:

$$
\frac{G_{t}}{Y_{t}}=\frac{G_{t+1}}{Y_{t+1}}
$$

Fiscal rule aims at stabilization of the fiscal deficit and public debt level, which is achieved by gradual return to targeted levels of these two variables by the following formula:

$$
B_{t}=B_{t-1}+\varphi_{1}\left(B_{t-1}-B_{t}^{T}\right)+\varphi_{2}\left(G_{t}-G_{t}^{T}\right)
$$

where $\mathrm{B}_{t}^{\mathrm{T}}$ is targeted level of public debt and $\mathrm{G}_{\mathrm{t}}^{\mathrm{T}}$ is targeted level of fiscal deficit. Speed of return to target is determined by the parameters $\varphi 1$ и $\varphi 2$. According to the Budgetary system law adopted in Serbia values for targets BT and GT are 45\% and $1 \%$, and for parameters $\varphi 1$ and $\varphi 2$ they are 0.3 and 0.4 , respectively.

\section{Data}

Model was estimated using two data sets, since some of the data series were available only for shorter periods of time. For the period since 2002 only data on gross domestic product and exchange rate are available on quarterly level. Data series for consumer price index is available starting from 2007. Finally, data series for banking interest rates are available starting from the Q3 2010. Aside from these, 
we used data from the banking sector balance sheet (loans and deposits), and from national accounts and balance of payments, private consumption, imports, exports and budget deficit. For the foreign economy we used the interest rate EURIBOR $2 \mathrm{~W}$ and the consumer price index.

Gross domestic product series was used in constant prices, seasonally adjusted and without linear trend. This is more common method of detrending than the alternative such as the HP filter, and has proven to give better results in our case, probably due to the problem of skewing at the end that the HP filtering can cause. Series was then transformed to match the model's percent deviation from the steady state in the following way:

$$
\hat{y}_{t}=\frac{r g d p}{r g d p-r g d p_{-} l t}-1
$$

where $r g d p$ is gross domestic product series in constant prices, seasonally adjusted and rgdp_lt is its linear trend. This transformation is in line with the model's deviations obtained by log-linearization in a way:

$$
X_{t}=\bar{X}\left(1+\hat{x}_{t}\right)
$$

Similarly, the exchange rate was transformed after seasonal adjustment and separating the trend and cyclical component:

$$
\hat{s}_{t}=\frac{s}{s-s_{-} l t}-1
$$

Data series for inflation is available only from 2007 since this is the year when the methodology of price index statistics was changed (from tracking retail prices to consumer price index). Since two indices are not comparable we only used the series from 2007 . We used annual growth rates with quarterly frequency, adjusting the data to the model the following way:

$$
\hat{\pi}_{t}=\frac{\pi^{q}}{\pi^{q}-\pi_{l t}^{q}}-1
$$

where

$$
\pi^{q}=\frac{\pi^{\mathrm{a}}}{4}
$$

and $\pi^{\mathrm{a}}$ is annual inflation rate. This is common methodology of transforming annual to quarterly rates although it would be more precise to transform the data by the formula: 


$$
\pi^{q}=\left[\left(\frac{1+\pi^{m}}{100}\right)\left(\frac{1+\pi^{m-1}}{100}\right)\left(\frac{1+\pi^{m-2}}{100}\right)-1\right]
$$

where $\pi^{\mathrm{m}}$ is the monthly inflation rate. Reason that the first method is used can be found in the fact that the agents do not observe the inflation directly but based on official statistics reported at annual level. They form their expectations also on an annual level so it is more acceptable from the modelling perspective to assume that the agents are perceiving quarterly rate of inflation as a quarter of annual inflation then as a cumulative effect of three monthly rates of inflation.

Another option to adjust inflation data series to the model is to transform it to deviations from average inflation rate, but we chose the linear trend deviations instead, same as for the other series.

Interest rate series are available only since October 2010. Data for the previous period are aggregated for dinar and euro-indexed loans (and deposits) which makes the series unusable. Also, there was no distinction between new loans and total loans interest rates, which also impairs reliability of the data. For this reason we only used interest rates data for the period beginning as of Q32010, which has shortened the length of a series considerably (to 21 periods).

We used series for interest rates on dinar and euro deposits of households, and dinar and euro loans to firms, which corresponds to the model variables $\mathrm{i}_{t}^{\mathrm{dd}}, \mathrm{i}_{\mathrm{t}}^{\mathrm{fd}}$, $\mathrm{i}_{\mathrm{t}}^{\mathrm{dl}}$ and $\mathrm{i}_{\mathrm{t}}^{\mathrm{fl}}$. We used rates for the maturity of one year, deciding it best illustrates the settings of the model, and we seasonally adjusted the series, where necessary.

Private consumption is taken from the national accounts statistics of the National Statistics Office. Fiscal deficit is taken from the Ministry of Finance statistics and refers to consolidated budget. Both are real, seasonally adjusted and decomposed to linear trend and cyclical component.

Total debt and its dinar and euro components refer to private companies debt owed to the banks, public companies debt is omitted in the model as is the household debt. Total and dinar and euro denominated savings refer to savings of the households, while the company savings are omitted. Dinar denominated series is used in dinars and euro in accordance with the model specifications.

\section{Estimation}

We estimated the model using Bayesian techniques, i.e. using beliefs about the distribution of the model's parameters. We used Dynare package for the estima- 
tion, estimating the model by Monte Carlo Markow Chain sampling techniques. There are two main advantages to using Bayesian estimation for the DSGE models. First, this method allows us to estimate the model as a whole as opposed to estimation of its equations one by one (as would be done if we estimated, for example, a consumption Euler equation by VAR techniques), and secondly Bayesian estimation allows us to use priors, i.e. beliefs about the values and distributions of the model's parameters. This is especially important when one is estimating a large number of parameters, which is inevitable in any model attempting to illustrate the working of an economy. These and other advantages of Bayesian estimation of DSGE models are a subject of several papers, such as Schorfheide (2000), Smets, Wouters (2003), Rabanal, Rubio-Ramirez (2003), Fernandez-Villaverde, Rubio-Ramirez (2003, 2004), Lubik, Schorfheide (2007), An, Schorfheide (2007) Edge at al (2010). Here we shall review theoretical background for the application of this method.

\section{Estimation results}

We estimated the model on two sets of data. Since data on interest rates is available only since Q32010, we estimated the model on a full set of data for a (small) sample of 21 periods. We estimated the combinations of monetary and fiscal policies, namely inflation targeting in combination with discretionary fiscal policy, procyclical fiscal policy and fiscal rules, and fixed exchange rate regime again in combination with discretionary fiscal policy, procyclical fiscal policy and fiscal rules. Judging by the log data density, data is best described by the model combining inflation targeting with discretionary fiscal policy, log data density value for this estimation is 203.759. ${ }^{2}$ This does not surprise that much as fiscal rules were violated continuously in the observed period, rendering budget deficit more of a random process and fiscal policy discretionary rather than regulated by rules.

Residuals of this estimated model shown in the next set of graphs do not oscillate ideally around zero but the return to zero is noticeable. One should note that the Bayesian estimation of DSGE models does not require a sum of residuals to be equal to zero, like in the case of LS estimator, but systematic deviation from zero can point to a model misspecification. In order to show that the model is not misspecified we estimated it on a longer sample of data, since 2007, but without

\footnotetext{
2 Log data density for the model with fiscal rules is -291.2 , thus not dramatically different but still inferior to the model with discretionary fiscal policy. The other two monetary and fiscal policy combinations do not produce reliable estimates.
} 
the financial series (i.e. banking interest rates), where we show that the residuals oscillation around zero is much more regular. ${ }^{3}$

\section{Graph 1: Estimated DSGE model residuals}
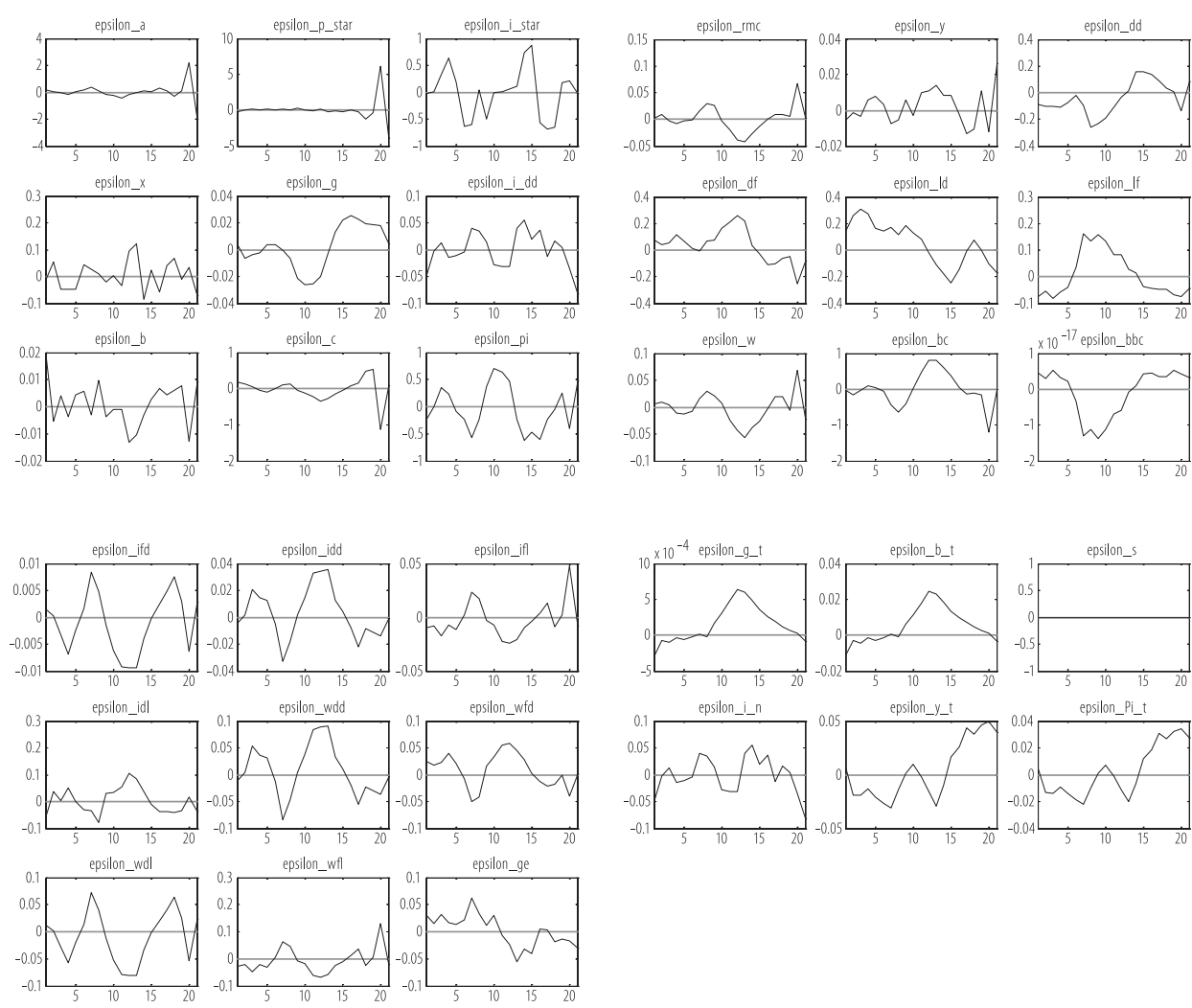

Estimated prior and posterior distributions are shown in the next graphs, vertical green line represents the posterior mode, while grey and black lines represent prior and posterior distributions of the estimated parameter. All distributions are approximately normally distributed, or at least not displaying multiple maxima or minima, which is the first indication that the model properly describes the data. The third and fourth set of graphs show estimations of "deep" parameters, and we see that for the parameters $\alpha$ and $\omega$ data points to values significantly different from our assumptions, so that the estimated $\omega$ is around 0.6 a not 0.45 as we guessed, meaning that the firms change prices much closer to the frequency

\footnotetext{
${ }^{3}$ These residuals are presented in an Appendix.
} 
observed in developed countries (where usual estimated value for this parameter is 0.5 to 0.75 ). On the other hand $\alpha$ - labour productivity elasticity, is closer to 0.8 and not to 0.45 as we assumed.

\section{Graph 2: Prior and posterior distribution of the estimated DSGE parameters}

Table 1: Statistical moments of the estimated parameters

\begin{tabular}{|c|c|c|c|c|c|c|}
\hline parameter & prior mean & $\begin{array}{c}\text { posterior } \\
\text { mean }\end{array}$ & \multicolumn{2}{|c|}{$90 \%$ HPD interval* } & $\begin{array}{c}\text { prior } \\
\text { distribution }\end{array}$ & $\begin{array}{l}\text { posterior } \\
\text { deviation }\end{array}$ \\
\hline Beta & 0,990 & 0.9898 & 0.9867 & 0.9934 & beta & 0.0020 \\
\hline Chi & 0.900 & 0.9058 & 0.8742 & 0.9371 & beta & 0.0200 \\
\hline Alpha & 0.400 & 0.7195 & 0.6430 & 0.7946 & beta & 0.2000 \\
\hline Omega & 0.450 & 0.6237 & 0.5041 & 0.7520 & beta & 0.2000 \\
\hline Ka_dd & 6.000 & 5.9407 & 5.1479 & 6.7611 & norm & 0.5000 \\
\hline Ka_fd & 5.000 & 5.2765 & 4.5400 & 6.0137 & norm & 0.4500 \\
\hline Ka_fl & 5.000 & 5.3970 & 4.7227 & 6.1020 & norm & 0.4500 \\
\hline Ka_dl & 6.000 & 6.1593 & 5.3559 & 6.9753 & norm & 0.5000 \\
\hline Eta_dl & 3.000 & 2.9588 & 2.7090 & 3.2021 & norm & 0.1500 \\
\hline Eta_fl & 3.000 & 2.8745 & 2.6247 & 3.1303 & norm & 0.1500 \\
\hline Eta_dd & 2.000 & 2.0299 & 1.6965 & 2.3409 & norm & 0.2000 \\
\hline Eta_fd & 2.000 & 1.8963 & 1.5438 & 2.2355 & norm & 0.2000 \\
\hline Fi1 & 0.300 & 0.1634 & 0.0458 & 0.2902 & beta & 0.1500 \\
\hline $\mathrm{Fi} 2$ & 0.400 & 0.2429 & 0.0135 & 0.4619 & beta & 0.2000 \\
\hline Rho_a & 0.950 & 0.9546 & 0.9288 & 0.9816 & beta & 0.0200 \\
\hline Rho_p_star & 0.950 & 0.7541 & 0.7291 & 0.7779 & beta & 0.0200 \\
\hline Rho_i_star & 0.950 & 0.9392 & 0.9036 & 0.9768 & beta & 0.0200 \\
\hline Rho_y_t & 0.950 & 0.9445 & 0.9125 & 0.9783 & beta & 0.0200 \\
\hline Rho_Pi_t & 0.950 & 0.9480 & 0.9172 & 0.9805 & beta & 0.0200 \\
\hline Rho_g_t & 0.950 & 0.9493 & 0.9192 & 0.9816 & beta & 0.0200 \\
\hline Rho_b_t & 0.950 & 0.9476 & 0.9166 & 0.9793 & beta & 0.0200 \\
\hline
\end{tabular}

Note: ${ }^{*} 90 \%$ HPD interval is the $90 \%$ interval of the posterior density distribution.

Multivariate convergence diagnostics according to Brooks and Gelman (1992) methodology shows satisfactory convergence and stabilization. Univariate convergence shows more variation but convergence is achieved.

Acceptance ratio for the first Monte Carlo chain is $34.1697 \%$, and for the second one it is $34.5797 \%$, which is in accordance with the literature recommended third of sample, see Roberts, Gelman and Gilks (1997). 
Graph 3: Multivariate convergence diagnostics according to Brooks and Gelman methodology

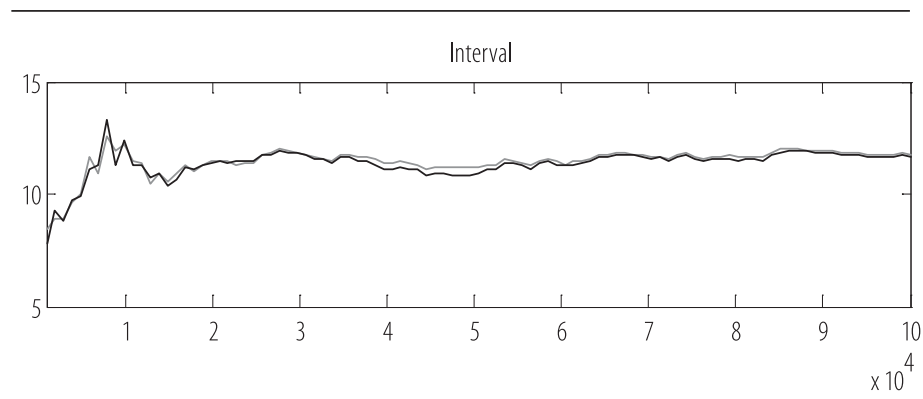

m2



m3

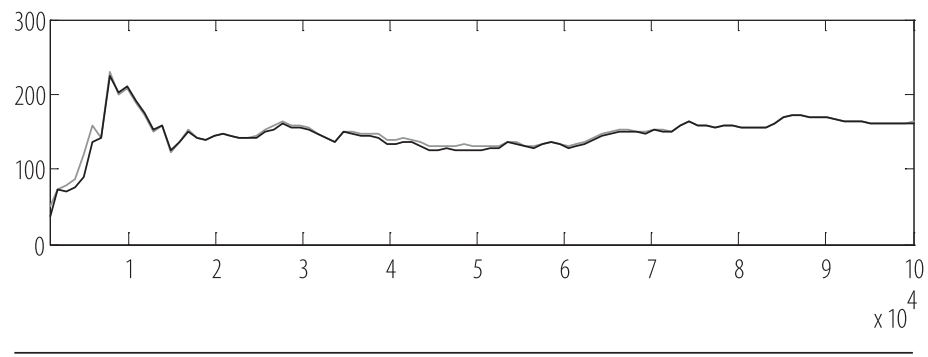

\section{Conclusion}

We propose a model for monetary and fiscal policy coordination analysis in a small open economy with high financial dollarization and estimate it on data for Serbia. We use Bayesian estimation techniques having in mind their advantages, primarily the possibilities to use prior information and estimate the whole system jointly as opposed to estimating its individual parts, i.e. individual equations.

We estimate the model on two sets of data, one starting from 2010 and including the data on banking interest rates, and one starting from 2007 that omits the interest rate data. Even on a smaller sample of data, including banking interest 
rates, we get satisfactory estimation diagnostics and parameter estimates that are in line with the literature on the subject. On a longer sample (though without the interest rate data) we get good residuals behaviour, and consistent parameter estimates. We consider 6 combinations of monetary and fiscal policy regimes, inflation targeting and currency peg on one hand, and discretionary, cyclically neutral fiscal policy and fiscal rules, on the other hand. The model that combines inflation targeting and fiscal policy described as an AR process fits the data better than the one defining the fiscal rule as the data generating process for fiscal policy. This is not so unexpected given that the fiscal rules were violated continuously in the observed period. The rest of the monetary fiscal policy mix options cannot fit the data, again not so surprising having in mind that the observed period was marked by high exchange rate volatility.

It is possible to extend the model presented in the paper in various directions, to answer questions regarding monetary and fiscal policy, but also questions from other areas, such as the labour market. Obvious extensions that we briefly commented on can be made in the area of tax policy, and another option is to extend the model to include a more detailed bank balance sheet and then be able to answer questions regarding monetary policy prudential measures (for example questions regarding influence of mandatory reserves). By adding the government debt market one could analyse various issues in this area (crowding out effect of public spending for example). Our goal was to show that even with short time series available for the Serbian economy, one can produce an estimate for an elaborate DSGE model suitable for policy analysis. 


\section{References}

1. Alesina, A., \& Bayoumi, T. (1996). The costs and benefits of fiscal rules: evidence from US states (No. w5614). National bureau of economic research.

2. Alesina, A., Hausmann, R., Hommes, R., \& Stein, E. (1999). Budget institutions and fiscal performance in Latin America. Journal of development Economics, 59(2), 253-273.

3. Amato, J. D., \& Gerlach, S. (2002). Inflation targeting in emerging market and transition economies: Lessons after a decade. European Economic Review, 46(4), 781-790.

4. Ammer, J., \& Freeman, R. T. (1995). Inflation targeting in the 1990s: the experiences of New Zealand, Canada, and the United Kingdom. Journal of Economics and Business, 47(2), 165-192.

5. An, S., \& Schorfheide, F. (2007). Bayesian analysis of DSGE models. Econometric reviews, 26(2-4), 113-172.

6. Ayuso-i-Casals, J., Debrun, X., Kumar, M. S., Moulin, L., \& Turrini, A. (2007). Beyond the SGP-Features and effects of EU national-level numerical fiscal rules. The role of fiscal rules and budgetary institutions in shaping budgetary outcomes," European Economy- Economic Papers, 275.

7. Ball, L. M., \& Sheridan, N. (2004). Does inflation targeting matter?. In The inflation-targeting debate (pp. 249-282). University of Chicago Press.

8. Bernanke, B. S. (2001). Inflation targeting: lessons from the international experience. Princeton University Press.

9. Bernanke, B. S. (2001). Inflation targeting: lessons from the international experience. Princeton University Press.

10. Bernanke, B. S., \& Mishkin, F. S. (1997). Inflation targeting: a new framework for monetary policy? (No. w5893). National Bureau of Economic Research.

11. Brooks, S. P., \& Gelman, A. (1998). General methods for monitoring convergence of iterative simulations. Journal of computational and graphical statistics, 7(4), 434-455.

12. Calvo, G. A. (1983). Staggered prices in a utility-maximizing framework. Journal of monetary Economics, 12(3), 383-398.

13. Caceres, C., Corbacho, A., \& Medina, L. (2010). Structural Breaks in Fiscal Performance: Did Fiscal Responsibility Laws Have Anything to Do with Them?.

14. Cúrdia, V., \& Woodford, M. (2009). Credit Frictions and Optimal Monetary Policy: Technical Appendix. 
15. Dafflon, B., \& Pujol, F. (2001). Fiscal preferences and fiscal performance: Swiss cantonal evidence. International Public Management Review, 2(2), 5479.

16. Dewachter, H., \& Wouters, R. (2014). Endogenous risk in a DSGE model with capital-constrained financial intermediaries. Journal of Economic Dynamics and Control, 43, 241-268.

17. Dib, A. (2010). Banks, credit market frictions, and business cycles (No. 2010, 24). Bank of Canada Working Paper.

18. Edge, R. M., Kiley, M. T., \& Laforte, J. P. (2010). A comparison of forecast performance between federal reserve staff forecasts, simple reduced-form models, and a DSGE model. Journal of Applied Econometrics, 25(4), 720 754.

19. Fatás, A., \& Mihov, I. (2006). The macroeconomic effects of fiscal rules in the US states. Journal of public economics, 90(1), 101-117.

20. Feld, L. P., \& Kirchgässner, G. (2008). On the effectiveness of debt brakes: the Swiss experience. Sustainability of public debt, 223-255.

21. Filc, G., \& Scartascini, C. (2004, September). Budget institutions and fiscal outcomes: ten years of inquiry on fiscal matters at the Research Department. In presentation at the Research Department 10th Year Anniversary Conference. Office of Evaluation and Oversight. InterAmerican Development Bank.

22. Funk kIRkegAAR, J. (2012). General Government Net Indebtedness. Economic Challenges in an Era of Growing Multipolarity, 301.

23. Gali, J., \& Monacelli, T. (2000). Optimal monetary policy and exchange rate volatility in a small open economy. manuscript, Universitat Pompeu Fabra and Boston College.

24. Gali, J., \& Monacelli, T. (2005). Monetary policy and exchange rate volatility in a small open economy. The Review of Economic Studies, 72(3), 707-734.

25. Gerali, A., Neri, S., Sessa, L., Signoretti, F.M. (2009). Credit and Banking in a DSGE Model. In:Laxton D, Leon L (Eds): Macro-Linkages, Oil Prices and Deflation Workshop. IMF.

26. Giannoni, M. P., \& Woodford, M. (2010). Optimal target criteria for stabilization policy (No. w15757). National Bureau of Economic Research.

27. Gonçalves, C. E. S., \& Salles, J. M. (2008). Inflation targeting in emerging economies: What do the data say?. Journal of Development Economics, 85(1), 312-318.

28. Goodfriend, M., \& McCallum, B. T. (2007). Banking and interest rates in monetary policy analysis: A quantitative exploration. Journal of Monetary Economics, 54(5), 1480-1507. 
29. Hallerberg, M., Strauch, R., \& Von Hagen, J. (2007). The design of fiscal rules and forms of governance in European Union countries. European Journal of Political Economy, 23(2), 338-359.

30. Ireland, P. N. (2007). Changes in the Federal Reserve's inflation target: Causes and consequences. Journal of Money, credit and Banking, 39(8), 1851-1882.

31. Krogstrup, S., \& Wälti, S. (2008). Do fiscal rules cause budgetary outcomes?. Public Choice, 136(1-2), 123-138.

32. Lagona, F., \& Padovano, F. (2007). A nonlinear principal component analysis of the relationship between budget rules and fiscal performance in the European Union. Public Choice, 130(3), 401-436.Leiderman L. and Svensson L. E. O. 1995. eds. Inflation targets. London: Centre for Economic Policy Research.

33. Lubik, T. A., \& Schorfheide, F. (2007). Do central banks respond to exchange rate movements? A structural investigation. Journal of Monetary Economics, 54(4), 1069-1087.

34. Mishkin, F. S., \& Schmidt-Hebbel, K. (2001). One decade of inflation targeting in the world: what do we know and what do we need to know? (No. w8397). National bureau of economic research.

35. Neri, S., \& Ropele, T. (2015). Disinflationary shocks and inflation target uncertainty. Dynare Conference 2015. working papers.

36. Rabanal, P., \& Rubio-Ramírez, J. F. (2005). Comparing New Keynesian models of the business cycle: A Bayesian approach. Journal of Monetary Economics, 52(6), 1151-1166.

37. Roberts, G. O., Gelman, A., \& Gilks, W. R. (1997). Weak convergence and optimal scaling of random walk Metropolis algorithms. The annals of applied probability, 7(1), 110-120.

38. Schorfheide, F. (2000). Loss function-based evaluation of DSGE models. Journal of Applied Econometrics, 15(6), 645-670.

39. Smets, F., \& Wouters, R. (2003). An estimated dynamic stochastic general equilibrium model of the euro area. Journal of the European economic association, 1(5), 1123-1175.

40. Svensson, L. E. (1997). Inflation forecast targeting: Implementing and monitoring inflation targets. European economic review, 41(6), 1111-1146.

41. Svensson, L. E. (1999). Inflation targeting as a monetary policy rule. Journal of monetary economics, 43(3), 607-654.

42. Svensson, L. E. (2000). Open-economy inflation targeting. Journal of international economics, 50(1), 155-183.

43. Truman, E. M. (2003). Inflation targeting in the world economy. Columbia University Press. 


\section{Appendix}

Graph A1: Estimated DSGE model residuals (sample 2007-2016)
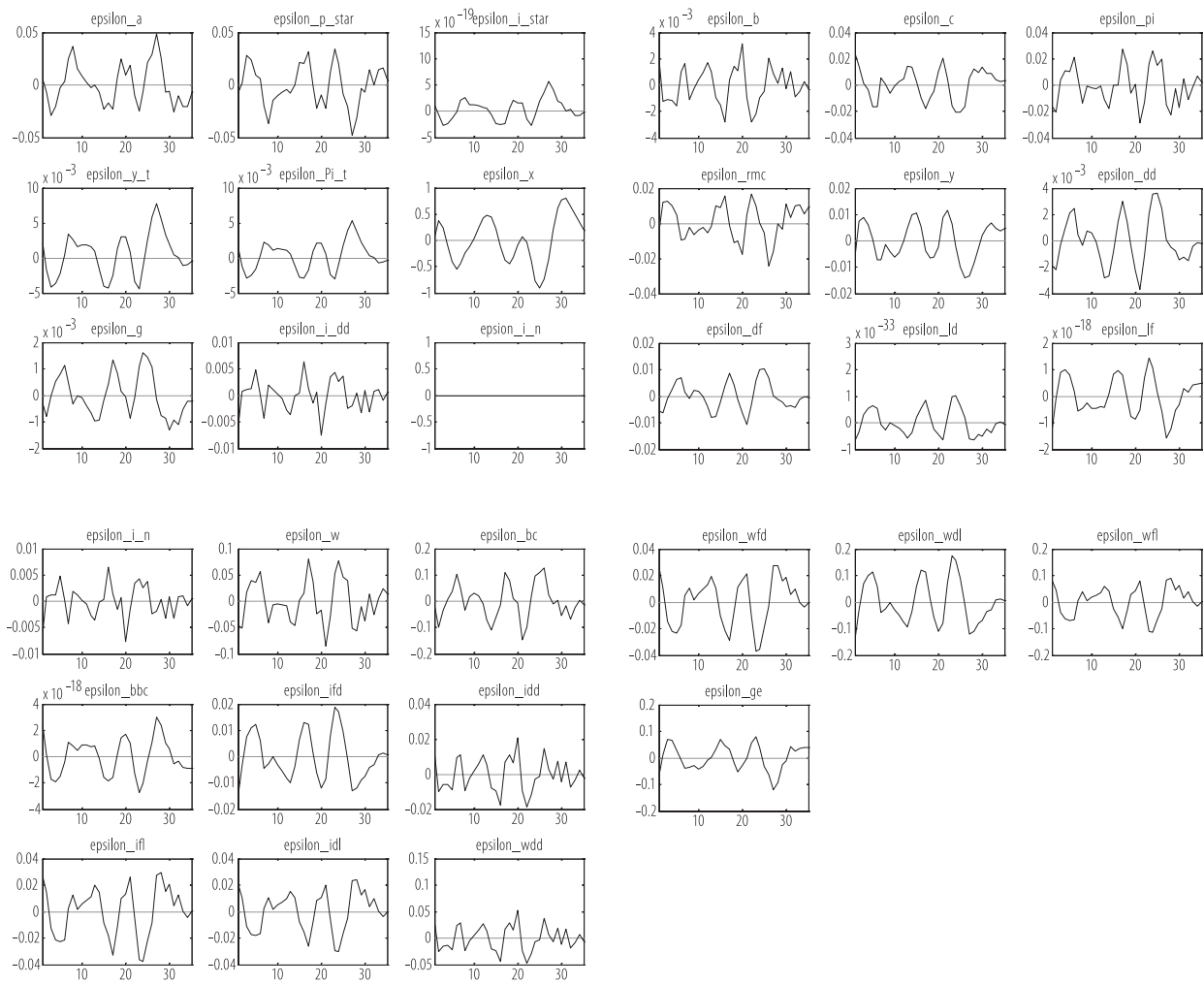